\title{
John Cahn Receives 1985 Von Hippel Award
}

The Materials Research Society has designated John W. Cahn, Senior Fellow at the National Bureau of Standards, as the 1985 recipient of the Von Hippel Award. In announcing the award, which will be presented on December 2 during the Society's Fall Meeting in Boston, MRS President Elton N. Kaufmann said, "The Society is pleased to present the Von Hippel Award to John Cahn because his accomplishments embody all that MRS seeks to advance, namely forefront interdisciplinary materials research. He is acknowledged as the outstanding theorist of the age in materials research, with a career over three decades that has seen pioneering work in a wide range of materials phenomena.

"He continues to be a vital researcher, as evidenced by his involvement in the recent discovery of quasi-crystalline phases - a discovery that promises to revolutionize our understanding of solids. In receiving the 1985 Von Hippel Award, he joins the ranks of the most distinguished researchers in modern materials science who have previously won the prize."

Past President Woody White, Chair of the Awards Committee, issued a statement that lauded Cahn as one of the intellectual giants of materials science: "Beginning with his classical work on spinodal decomposition, Cahn has made pioneering contributions to numerous and diverse areas of materials science. His work has been truly interdisciplinary, bringing together key

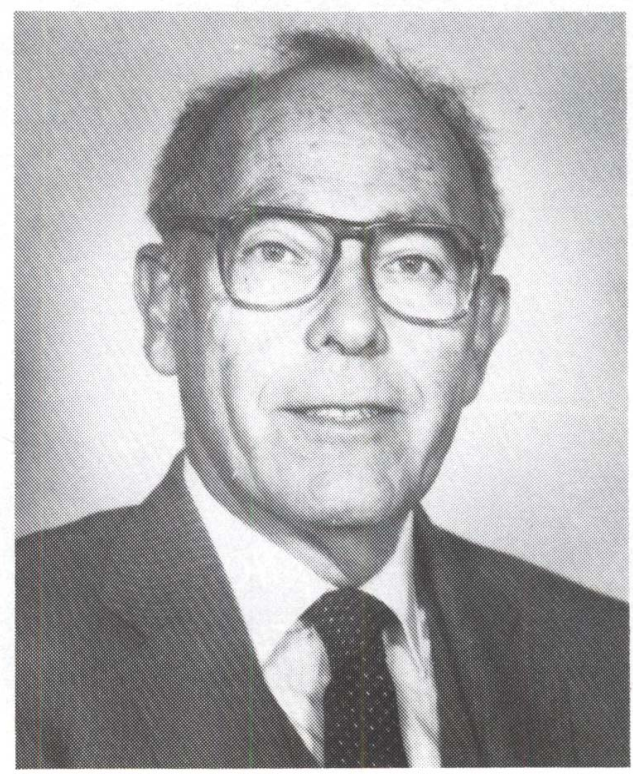

John W. Cahn

1985 Von Hippel Award recipient

aspects of chemistry, physics, metallurgy, and mathematics in studying critical problems in materials research. Cahn's research has had a significant influence on the research of hundreds of other individuals in the materials research community. He represents the special combination of attributes that the Von Hippel Award seeks to advance."
Dr. Cahn is a Senior Fellow at the Center for Materials Science, National Bureau of Standards, Gaithersburg, Maryland. He joined the NBS staff in 1978 after 14 years as professor of materials science at Massachusetts Institute of Technology. He began his research career as a research associate in the Holloman Metallurgy and Ceramics group of the General Electric Research Laboratory in Schenectady, New York, in 1954; he left G.E. in 1964 to accept the MIT appointment. He holds a BS in chemistry from the University of Michigan (1949) and $\mathrm{a} \mathrm{PhD}$ in physical chemistry from the University of California at Berkeley.

Dr. Cahn has influenced developments in materials science in a variety of ways, the most visible of which is his approximately 150 papers in archival journals, conference proceedings, and other scientific publications. He has also been very active as a visiting professor with appointments in Canada, Iran, Sweden, and Israel, as well as at several U.S. universities and major laboratories. He is a member of several professional societies, involved in societ y committees, editorial boards, and local sections. He has won numerous awards, including the Acta Metallurgica Gold Medal.

Dr. Cahn will be presented the Von Hippel Award on Monday, December 2, in a ceremony beginning at 6:30 p.m., followed by a lecture by Dr. Cahn. A reception for all meeting attendees will follow the award lecture.

\section{MIRS}

\section{THE VON HIPPEL AWARD}

The Von Hippel Award is the Materials Research Society's most prestigious award. It is presented annually to the living scientist who, in the Society's estimation, best exemplifies the originality, brilliance of intellect, and diligence of purpose throughout a career that are the hallmark of science at its best; who adheres to the strictist ethical standards and highest code of professional integrity; and whose vision transcends conventional disciplines, as does the science of materials itself.

The award consists of a svnthetic rubv crvstal suitably mounted, a cash honorarium, and a lifet ime membership in the Society. It is named for Arthur Robert von Hippel, emeritus professor of Massachusetts Institute of Technologv, who was also its first recipient.

The MRS Awards Committee solicits nominations annually from among the membership and elsewhere in the community of materials scientists. The nominees are evaluated against the Societv's criteria, rather than against each other. From among the candidates it has reviewed, the Awards Committee puts forward the names of the principal contenders for the honor. The nominees are considered in confidence by the Council of the Society. The Council, representative of the manv disciplines and institutions within MRS, makes the final decision bv a majoritv vote. 